\title{
Molecular Epidemiology of Escherichia Coli in HIV-Positive Individuals in South west Nigeria
}

\section{Abstract}

Introduction: Escherichia coli infection is a major health concern for human immunodeficiency virus (HIV)/AIDS patients because it is a substantial cause of diarrhoea-associated morbidity and mortality.

Materials and Methods: Stool and blood samples were collected from 879 HIVIAIDS patients in a tertiary hospital in southwest Nigeria. The blood samples were screened for HIV IgM using competitive ELISA, and the concentration of the IgM was determined. The stool samples were cultured on eosin methylene blue agar. The isolates were characterised based on the production of green metallic sheen on EMB agar. DNA was extracted from all the isolates, and the extracted DNA was analysed by PCR with primers specifically targeting the virulence genes of enterohemorrhagic $E$. coli (EHEC), enteropathogenic E. coli (EPEC), enterotoxigenic E. coli (ETEC), and enteroinvasive $E$. coli (EIEC). Statistical analysis was conducted using the openepi online epidemiological package.

Results: All the blood samples tested positive for HIV IgM antibodies, and $80 \%$ had high concentration. All the stool samples were positive for $E$. coli, based on cell culture and DNA extraction. Of all the DNA tested by PCR using gene-specific primers targeting the 4 strains of E. coli, 222 samples were positive for EHEC shiga toxin 1 (stx1) gene, 212 samples were positive for EPEC intimin (eaeA) gene, 289 were positive for EHEC serotype 0157:H7 using the stx2a\&b gene, 125 were positive for EIEC haemolysin (hlyA) gene, and 31 were positive for ETEC uid gene.

Discussion: The high prevalence of $E$. coli $\mathrm{O} 157: \mathrm{H7}$ is an indication that this strain, which has been previously linked with diarrhoea-related mortality in infants, may be responsible for most of the cases seen in HIVIAIDS patients. Though this strain is not common in adults,
Lawrence Ehis Okoror ${ }^{1}$, Duna Christina Fashina2, Titilayo Silifat Jimoh², Ezekiel Ayo Oisagah ${ }^{1}$

1 Department of Biological Sciences, Joseph Ayo Babalola University, Ikeji-Arakeji, Osun State, Nigeria.

2 Department of Medical Microbiology and Parasitology, Obafemi Awolowo University, Ife.

Contact information:

\section{Lawrence Ehis Okoror.}

Address: Department of Biological Sciences, Joseph Ayo Babalola University, Ikeji-Arakeji, PMB 5006, llesha, Osun State, Nigeria.

झ"LEOkoror@gmail.com

Keywords

ELISA, PCR, IgM, Culture, Primers, DNA extraction. 
its involvement in HIVIAIDS is indicative of suppressed immunity in this group of people. Other strains are also present in significant proportions, indicating that these strains also constitute a public health concern, because they may be transmitted to infants or other immunocompromised individuals.

\section{Introduction}

Chronic and persistent diarrhoea is a major cause of morbidity and mortality in people living with human immunodeficiency virus (HIV) and (AIDS). Diarrhoea occurs in almost $60-90 \%$ of people infected with HIV $[1,2]$. Enteropathy is a common feature in HIV/ AIDS patients [3] which can alter the lamina propia pre-disposing these patients to enteric pathogens and infections even when the pathogens are at low concentration, in contrast low pathogen levels in immune competent individuals will produce mild or asymptomatic infection [2].

A wide range of enteric pathogens has been implicated in diarrhoea in HIVIAIDS patients. Of these pathogens $E$. coli is strongly associated with persistence diarrhoea with different virulent factors such as adhesion; invasion; with production of toxins such as shiga-toxin and vibrio like toxins which are responsible for different types of diarrhoea produced by $E$. coli $[4,5]$. Six strains of $E$. coli are known and each strain is associated with a different type of diarrhoea-associated virulent factor encoded by different genes. Enterotoxigenic $E$. coli (ETEC) encode genes for heat labile and heat stable enterotoxins while the bundle forming pillus and intimin (attachment and effacing; eaeA) genes are encoded by enteropathogenic E. coli (EPEC). The invasion plasmid antigen $\mathrm{H}(i p a H)$ and haemolysin (hlyA); vibrio-like toxin) genes are encoded by enteroinvasive $E$. coli EIEC). Enterohaemorrhagic E. coli (EHEC) encodes shiga-like toxin I (s/tI) and shiga-like toxin II (s/tII), Enteroaggregative E. coli (Eagg-EC), and diffusely adherent E. coli (DAEC) encodes the encodes the afimbrial adhesin gene [2]. The st $\times 2 \mathrm{~A}$ and stx2B genes are encoded by EHEC 0157:H7 serotype (ECO157:H7) [6]. The uidA gene, which encodes the beta-glucuronidase can be used to identify EPEC.

In Nigeria, there have been a couple of studies on $E$. coli but none have characterised $E$. coli using molecular methods except a study by Okeke et al. [7] using hybridization technique and there study was from a different population. Though some studies have screened for some strains of E. coli, using the culture and serological methods and DNA hybridization, this will be the first molecular characterization (e.g. genotyping) of $E$. coli in HIV positive individuals. Vieira et al., [8] reported a high prevalence of EIEC in a remote town in Ecuador using PCR.

\section{Methods}

\section{Patients}

Blood $(n=879)$ and stool $(n=879)$ samples were collected from individuals screened for HIVIAIDS at a tertiary health institution. All the subjects gave informed consent by filling out questionnaire. Subjects were in four groups; HIV positive patients with diarrhoea $\left(\mathrm{HIV}^{+} \mathrm{Dia}^{+}\right)$; HIV positive without diarrhoea $\left(\mathrm{HIV}^{+} \mathrm{Dia}^{-}\right)$; HIV negative with diarrhoea $\left(\mathrm{HIV}^{-} \mathrm{Dia}^{+}\right)$; HIV negative without diarrhoea (HIV-Dia-). Stool samples were collected from individuals positive and negative for HIV IgM antibodies, and negative samples acted as the control. The control subjects had no history of diarrhoea at least a month prior to 
clinical screen whether or not they were $\mathrm{HIV}^{+}$. Subjects were defined as HIV positive with diarrhoea (Dia ${ }^{+} \mathrm{HIV}^{+}$; diarrhoea cases were defined as having frequent stooling more than 3 times a day), HIV positive and diarrhoea negative ( $\left.\mathrm{Dia}^{-} \mathrm{HIV}^{+}\right)$, HIV negative and diarrhoea positive ( $\left.\mathrm{Dia}^{+} \mathrm{HIV}^{-}\right)$, HIV negative and diarrhoea negative ( $\mathrm{Dia}^{-} \mathrm{HIV}^{-}$). Though this study did not include a matched case control stu$\mathrm{dy}$, questionnaire data collected from $\mathrm{HIV}^{+}$subjects included age, sex, marital status, socio-economic status, medical history, access to portable water, and contact with animals.

\section{Blood processing}

The blood samples were screened for HIV 1 and 2 positivity using the ELISA kit as per the manufacturer's instruction (WKEA Medical Supplies, China). The blood samples were collected into sterile vacutaners and immediately centrifuged at 3000 rpm at room temperature (Beckman 12), and sera were separated from all the samples and then stored at $-4^{\circ} \mathrm{C}$. At the start of ELISA, the serum and the ELISA kits were allowed to come to room temperature. The IgM antibodies to both HIV 1 and 2 were detected by absorbance measurement in a Thermomax Microplate Reader (Molecular Devices, CA, USA); cut-offs were calculated as described by the manufacturer.

\section{Stool processing}

The stool samples were collected into sterile container; samples $(1 \mathrm{~g})$ were diluted in $9 \mathrm{~mL}$ of sterile water added to it to start a serial dilution process and 10-fold serial dilutions were carried out. From each of the dilutions, $0.1 \mathrm{~mL}$ was transferred onto eosin methylene blue agar using the pour-plate method and incubated at $37^{\circ} \mathrm{C}$ for $24 \mathrm{~h}$. Those positive for $E$. coli were further confirmed by Gram staining, catalase, indole, coagulase, oxidase, urease, gelatinase, niterate reduction, methyl red and Voges-Proskauer, citerate utilization, motility, and sugar fermentation (glucose, lactose, maltose, su- crose, mannitol, fructose, and inositol). All confirmed E. coli culture were sub-cultured into Luria broth for DNA extraction.

\section{DNA extraction and PCR}

For DNA extraction, approximately $1000 \mu \mathrm{L}$ of the broth was placed into Eppendoff microfuge tubes and centrifuged for 10 minutes at 10000 rpm for 5 minutes, and then pellets were re-suspended in TE buffer. DNA was extracted was using a DNA extraction kit for bacteria (Norgen Biotek, Canada) as directed by the manufacturer. Primers for PCR were custom designed using Biology Work bench with default parameters and all the gene sequences used for primer design were obtained from the Genbank. PCR was performed to amplify the following genes using the primers as follows:- for uidA (5'-GACGACTTGGTTGTGGAGGT-3' and 5'-ATCCCCCTAAATCGATCACC-3') encoded by ETEC generating a 921 bp product; , for stx2a\&b (5'-TATATCAGTGCCCGGTGTGA-3' and 5'-TGTGACAGTGACAAACGCA-3') encoded by $E$. coli 0157:H7 strain and designed from gene sequence SM-25(1) stx-2 subunit A (stx2A) and stx2B complete CDS, generating a 1241 bp product,; for shiga toxin 1 gene (stx1) (5'-TGGTTGCGAAGGAATTTACC-3'and 5'-TGTGAAAAATCAGCAAAGCG-3') encoded by the EHEC FE94195 strain and designed from partial st 1 gene for shiga toxin 1 strain, generating 624 bp product; for haemolysin (hlyA) (5'-ATGCCTATTTCCGTGAGTGG-3' and 5'-CATTCTTCGCATTACGCTCA-3') encoded by the Vibrio cholerae strain ATCC 14035 and designed from hlyA partial CDS, generating a 415 bp product; , and for eaeA (5'-CAGCAAATCGAGCCACAGTA-3' and 5'-ACGATCCAGACCGTATTTGC-3') encoded by EPEC strain E3-8- and designed for intimin gene partial CDS, generating a 918 bp product. Primers for Eagg (5'CTGGCGAAAGACTGTATCAT-3' and 5'-CAATGTATAGAAATCCGCTGTT-3') and ipaH (5'-GCTGGAAAAACTCAGTGCCT-3' and 5'-CCAGTCCGTAAATTCATTCT-3) were pre-desig- 
ned [2] for the virulent strains EaggEC and DAEC respectively and were obtained commercially (Inqaba, South Africa). DNA was amplified using PCR 2X Master Mix (Norgen Biotek, Canada) in a Hybaid Omnigene Thermocycler with the following condition: 1 cycle of denaturation at $950 \mathrm{C}$ for 3 mins and 40 cycles of annealing for $30 \mathrm{~s}$ at $550 \mathrm{C}$, and enlongation at $720 \mathrm{C}$ for 5 mins. and 1 cycle of final enlongation for $1 \mathrm{~min}$.

\section{Results}

Of the 879 stool samples screened for 5 different strains of $E$. coli based on virulence genes, 574 (62.2\%) were $\mathrm{HIV}^{+}$of which 390 (67.7\%) were from $\mathrm{Dia}^{+} \mathrm{HIV}^{+}$patients and 186 (32.3\%) were from $\mathrm{Dia}^{-} \mathrm{HIV}^{+}$patients. Another 301 stool samples were from $\mathrm{HIV}^{-}$subjects, where 134 (63.8\%) were $\mathrm{Dia}^{+} \mathrm{HIV}^{-}$and 76 (36.2\%) were Dia-HIV-. The concentration of HIV IgM antibodies was higher in $\mathrm{Dia}^{+} \mathrm{HIV}^{+}$samples than in $\mathrm{Dia}^{-} \mathrm{HIV}^{+}$samples (Table 1), with the likelihood of having diarrhoea increasing as IgM concentration increase (Confidence Interval $(\mathrm{Cl})=99 \%)$. All culture were positive for production of gas in glucose, galactose and lactose; they were positive for motility, indole, and methyl red. The finger print of all the PCR products was able to detect the genes targeted by each primer with varying prevalence (Fig. 1A-E). Age and sex were not associated with prevalence of diarrhoea in $\mathrm{HIV}^{-}$positive individuals as was the case without HIV ( $\mathrm{Cl}=99 \%)$, nor did increased IgM depend on age or sex (Table 2). The strain specific virulent genes detectable in $\mathrm{HIV}^{+}$and in some controls samples and strain 0157:H7 more frequently isolated in both cases and control compared with other strains. EaggEC and DAEC were not detected while ETEC and EIEC were detected with low frequency. And ETEC was not extracted in $\mathrm{Dia}^{-} \mathrm{HIV}^{-}$individuals. Multiple genes were detected in $\mathrm{Dia}^{+} \mathrm{HIV}^{+}$as against only 2 in $\mathrm{Dia}^{+} \mathrm{HIV}^{-}$(Table 3). According to odds- based estimate, (Table 4)
0157:H7 (Odd Ratio, OR=1.736), EPEC (OR=1.595) and EHEC (OR=1.338) were most frequently associated with diarrhoea in the population .OR for all the multiple genes could not be determined because of too few or lack samples bearing multiple of $E$. coli genes. The etiological fraction (EF) of the general population (EFp/OR) was 27.54\% (lower limit $=6.605$ and upper limit $=48.48$ ) and the EF/OR in $\mathrm{HIV}^{+}$patients was $36.91 \%$ (lower limit=3.291 and upper limit= 58.84).

Table 1. Concentration of HIV IgM in infected individuals with or without diarrhoea.

\begin{tabular}{|c|c|c|c|c|c|}
\hline $\begin{array}{c}\text { IgM } \\
\text { Conc. }\end{array}$ & $\begin{array}{c}\text { No. } \\
\text { Dia }^{+}\end{array}$ & $\begin{array}{c}\text { No. } \\
\text { Dia- }\end{array}$ & Total & $\begin{array}{c}\text { Odds of } \\
\text { Exp. }\end{array}$ & $\begin{array}{c}\text { Odds } \\
\text { Ratio }\end{array}$ \\
\hline 20 & 70 & 80 & 150 & 0.88 & 1 \\
\hline 30 & 90 & 50 & 140 & 1.8 & 2.06 \\
\hline 40 & 120 & 30 & 150 & 4 & 4.57 \\
\hline 50 & 70 & 21 & 91 & 3.33 & 3.81 \\
\hline 60 & 30 & 5 & 35 & 6 & 6.86 \\
\hline 80 & 10 & 0 & 10 & 'undefined' & 'undefined' \\
\hline Total & 390 & 186 & 576 & & \\
\hline
\end{tabular}

Table 2. Co-founding different HIV IgM concentrations using Mantel-Haenszel Summary Odds Ratios (OR) and Crude OR for concentration using the lowest concentration as baseline.

\begin{tabular}{|c|c|c|}
\hline IgM Concs. & $\begin{array}{c}\text { MH Summary } \\
\text { OR }\end{array}$ & Crude OR \\
\hline 20 vs. 20: & 1 & 1 \\
\hline 30 vs. 20: & 2.057 & 2.057 \\
\hline 40 vs. 20: & 4.571 & 4.571 \\
\hline 50 vs. 20: & 3.81 & 3.81 \\
\hline 60 vs. 20: & 6.857 & 6.857 \\
\hline 80 vs. 20: & 'undefined' & 'undefined' \\
\hline $\begin{array}{l}\text { Extended Mantel-Haenzel Chi square for linear trend } \\
=46.08 \text { P-value for one degree of freedom }=<0.0000001\end{array}$
\end{tabular}


Table 3. Distribution of $E$. coli strains identified by their virulence genes isolated from HIV-positive and HIV-negative individuals with or without diarrhoea.

\begin{tabular}{|c|c|c|c|c|c|c|c|c|}
\hline \multirow{2}{*}{ Virus strains } & \multicolumn{2}{|c|}{ No. of Cases (\%) } & \multicolumn{2}{|c|}{ No. of controls (\%) } & \multicolumn{2}{|c|}{ Fisher Exact $p$ value } & \multicolumn{2}{|c|}{$\begin{array}{l}\text { Mid-Point Exact } \\
\text { p value }\end{array}$} \\
\hline & $\begin{array}{l}\mathrm{Dia}^{+} \mathrm{HIV}^{+} \\
(\mathrm{n}=490)\end{array}$ & $\begin{array}{l}\mathrm{Dia}^{+} \mathrm{HIV}^{-} \\
(n=134)\end{array}$ & $\begin{array}{l}\text { Dia- HIV }^{+} \\
(n=183)\end{array}$ & $\begin{array}{l}\text { Dia- HIV- }^{-} \\
(n=76)\end{array}$ & 1-tail & 2-tail & 1-tail & 2-tail \\
\hline \multicolumn{9}{|l|}{ Education } \\
\hline EPEC & $98(75.4)$ & $32(24.6)$ & 48(65.8) & $25(34.2)$ & 0.09698 & 0.1940 & 0.07481 & 0.1496 \\
\hline EHEC & $142(74.3)$ & $49(25.9)$ & $52(68.4)$ & $24(31.6)$ & 0.2030 & 0.4060 & 0.1661 & 0.3322 \\
\hline ETEC & 16(94.1) & $1(5.9)$ & $9(100)$ & $0(0)$ & $0.6538(P)$ & $>0.9999999$ & $0.3269(P)$ & 0.6538 \\
\hline EIEC & $30(85.7)$ & $5(14.3)$ & $9(90)$ & $1(10)$ & $0.5978(\mathrm{P})$ & $>0.9999999$ & $0.3986(P)$ & 0.7971 \\
\hline ECO157:H7 & $204(81.3)$ & $47(18.7)$ & $65(71.4)$ & $26(28.6)$ & 0.03676 & 0.07353 & 0.02785 & 0.05570 \\
\hline \multicolumn{9}{|l|}{ Multiple } \\
\hline EPEC and EHEC & $11(91.7)$ & $1(8.3)$ & - & - & & & & \\
\hline EPEC and EIEC & $1(100)$ & - & - & - & $0.8889(\mathrm{P})$ & $>0.9999999$ & & \\
\hline EIEC and EHEC & $1(100)$ & - & - & - & & & & \\
\hline $\begin{array}{l}\text { EIEC and } \\
\text { ECO157:H7 }\end{array}$ & $3(100)$ & - & - & - & & & & \\
\hline $\begin{array}{l}\text { EPEC and } \\
\text { ECO157:H7 }\end{array}$ & $31(88.6)$ & $4(11.4)$ & $1(100)$ & - & & & & \\
\hline $\begin{array}{l}\text { EPEC, EHEC } \\
\text { and ECO157:H7 }\end{array}$ & $7(77.8)$ & $2(22.2)$ & $1(100)$ & - & $0.8000(P)$ & $>0.9999999$ & $0.4000(P)$ & 0.8000 \\
\hline Crude & $544(79.4)$ & $141(20.6)$ & 185(70.9) & $76(29.1)$ & 0.003827 & 0.007654 & 0.003060 & 0.006121 \\
\hline Adjusted & & & & & 0.01353 & 0.02705 & 0.01108 & 0.02216 \\
\hline
\end{tabular}

Table 4. Odds-based estimates and confidence limits of genes associated with different strains of diarrheagenic E. coli.

\begin{tabular}{|l|c|c|c|c|c|c|}
\hline \multirow{2}{*}{ Virulence strains } & \multirow{2}{*}{ Odd Ratio } & Confidence Limit (99\%) & \multicolumn{2}{c|}{ Mid-Point Exact } \\
\hline EPEC & \multicolumn{2}{|c|}{ Fisher Exact } & \multicolumn{2}{c|}{ Mid-Por } \\
\hline EHEC & 1.595 & Lower & Upper & Lower & Upper \\
\hline ETEC & 1.338 & 0.6617 & 3.799 & 0.69 & 3.647 \\
\hline EIEC & 0.0 & 0.5867 & 2.964 & 0.6095 & 2.863 \\
\hline ECO157:H7 & 0.6667 & 0.0 & 375.9 & 0.0 & 187 \\
\hline EPEC and EHEC & 1.736 & 0.002508 & 12.48 & 0.005014 & 10.16 \\
\hline EPEC and EIEC & undefined & 0.7938 & 3.696 & 0.8221 & 3.581 \\
\hline EIEC and EHEC & 0.0 & - & - & - & - \\
\hline EIEC and ECO157:H7 & undefined & 0.0 & 1592 & - & - \\
\hline EPEC and ECO157:H7 & undefined & - & - & - & - \\
\hline EPEC, EHEC and ECO157:H7 & undefined & - & - & - & - \\
\hline All Strains & 0.0 & - & - & - & - \\
\hline
\end{tabular}




\begin{tabular}{|c|c|c|c|c|c|}
\hline \multirow{3}{*}{ Virulence strains } & \multirow{3}{*}{ Odd Ratio } & \multicolumn{2}{|c|}{ Confidence Limit (99\%) } & \multirow{2}{*}{\multicolumn{2}{|c|}{ Mid-Point Exact }} \\
\hline & & \multicolumn{2}{|c|}{ Fisher Exact } & & \\
\hline & & Lower & Upper & Lower & Upper \\
\hline \multirow[t]{5}{*}{ Crude } & CMLE Odds Ratio* & 1.584 & $1.029,2.423^{1}$ & Mid-P Exact & \\
\hline & & & $1.016,2.453^{1}$ & Fisher Exact & \\
\hline & Odds Ratio & 1.585 & $1.034,2.429^{1}$ & Taylor series & \\
\hline & Etiologic fraction in pop.(EFp|OR) & $27.54 \%$ & $6.605,48.48$ & & \\
\hline & Etiologic fraction in exposed(EFe|OR) & $36.91 \%$ & $3.291,58.84$ & & \\
\hline \multirow[t]{7}{*}{ Adjusted } & CMLE Odds Ratio* & 1.476 & $0.9515,2.276^{1}$ & Mid-P Exact & \\
\hline & & & $0.9391,2.304^{1}$ & Fisher Exact & \\
\hline & Directly Adjusted OR & '?' & '?', '?'1 & Taylor series & \\
\hline & Mantel-Haenszel OR & 1.48 & $0.9574,2.289^{1}$ & $\begin{array}{l}\text { Robins, } \\
\text { Greenland, } \\
\text { Breslow }\end{array}$ & \\
\hline & $\begin{array}{l}\text { Breslow-Day test for interaction of } \\
\text { Odds Ratio over strata: }\end{array}$ & & 2.964 & 0.6095 & \\
\hline & chi square $=$ & '?' & $p=$ & $\mathrm{NaN}$ & \\
\hline & $\begin{array}{l}\text { p greater than } 0.05 \text { does not } \\
\text { suggest interaction. Adjusted OR } \\
\text { can be used. }\end{array}$ & 0.002508 & 12.48 & 0.005014 & \\
\hline
\end{tabular}

Figure 1: a: PCR amplification pattern of shiga toxin 2 (stx2A and stx2B) subunit genes encoded by $E$. coli O157:H7

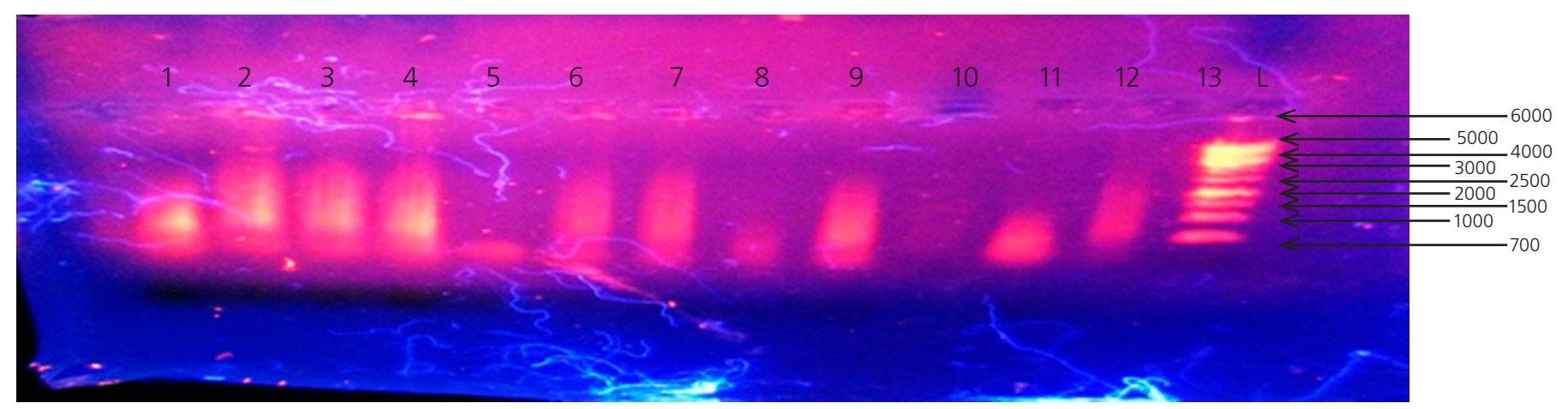

b: PCR amplification pattern of shiga toxin 1 gene (stx1) encoded by strain EHEC FE94195.

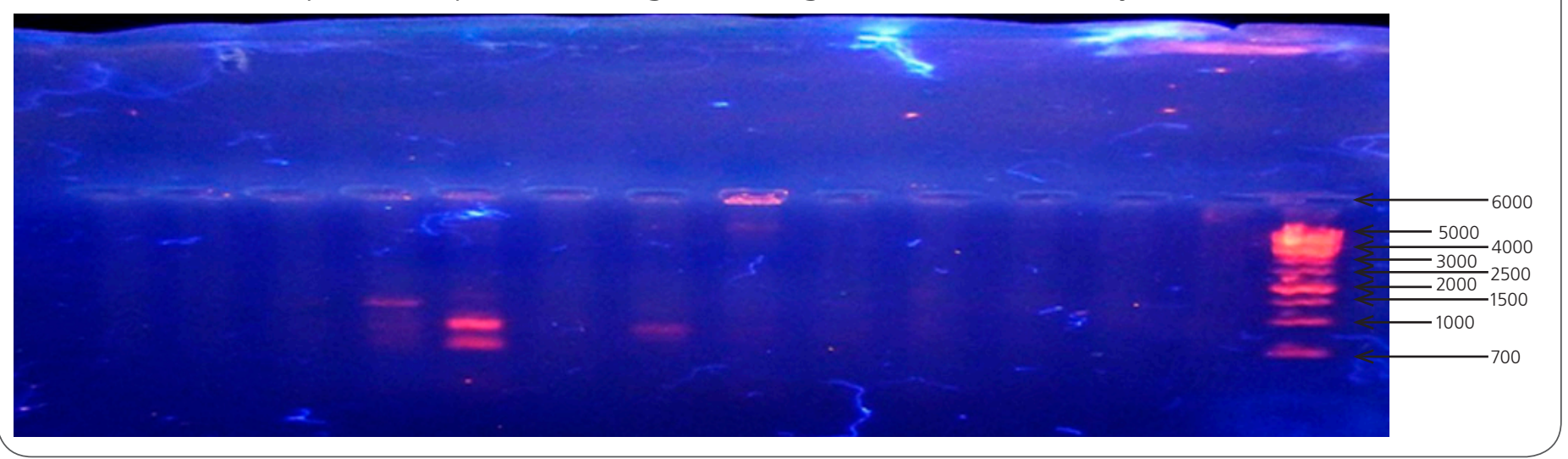


Figure 1: c: PCR amplification pattern of haemolysin gene (hlyA) encoded by ETEC.

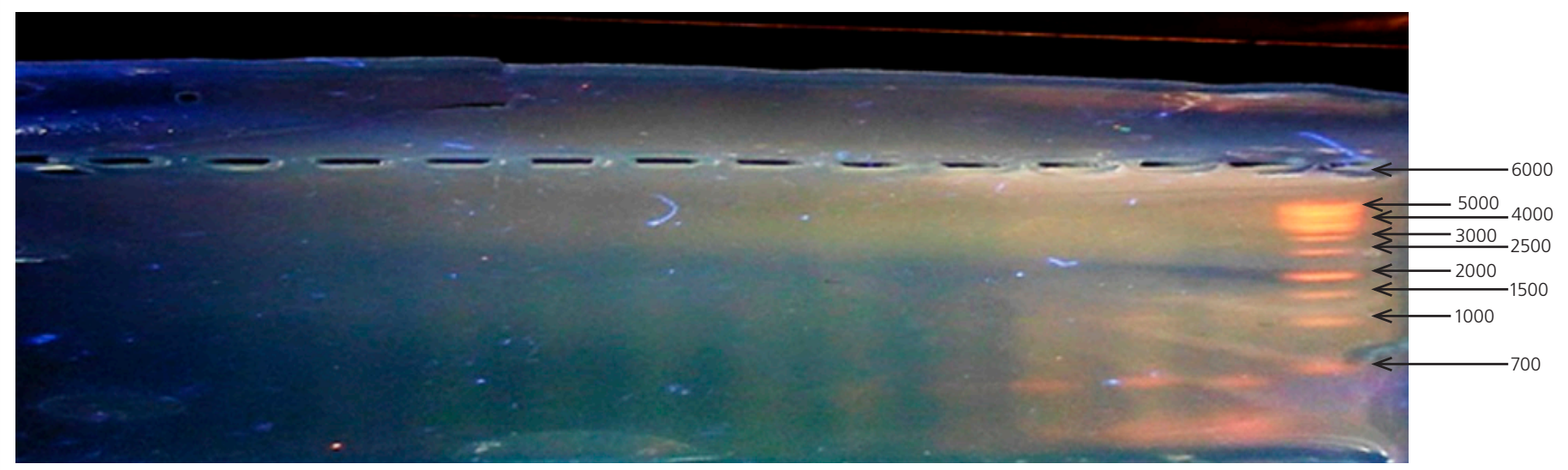

d: PCR amplification pattern of intimin gene (eaeA) encoded by EPEC.

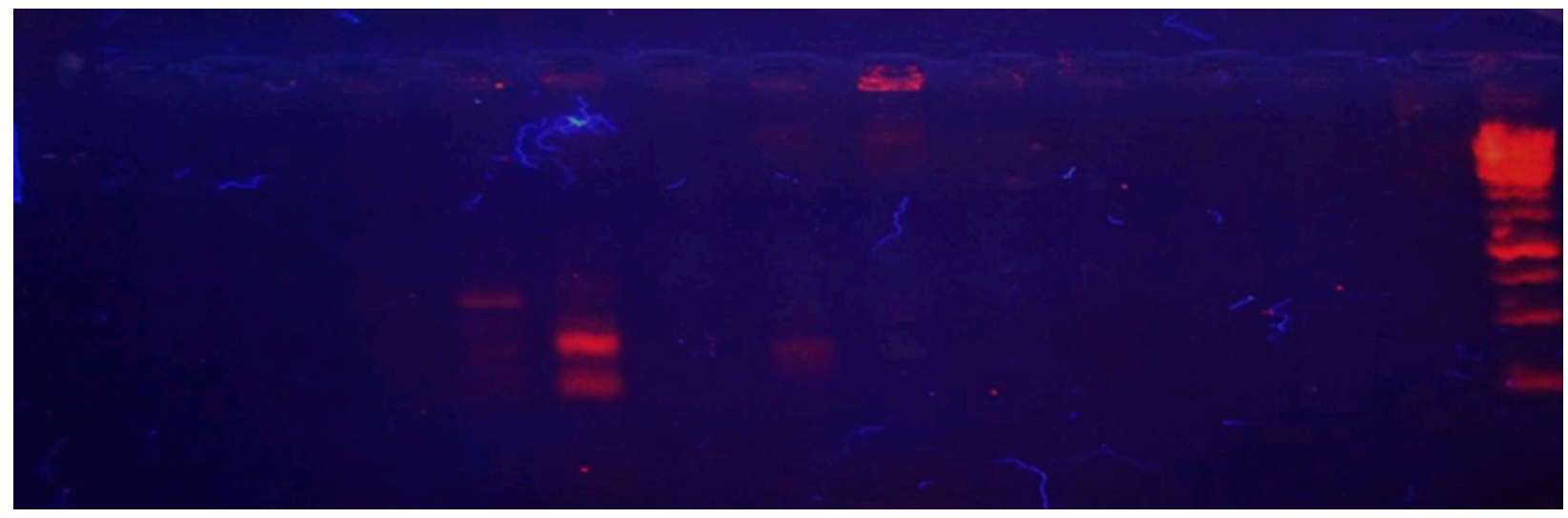

e: PCR amplification pattern of uid encoded by EIEC.

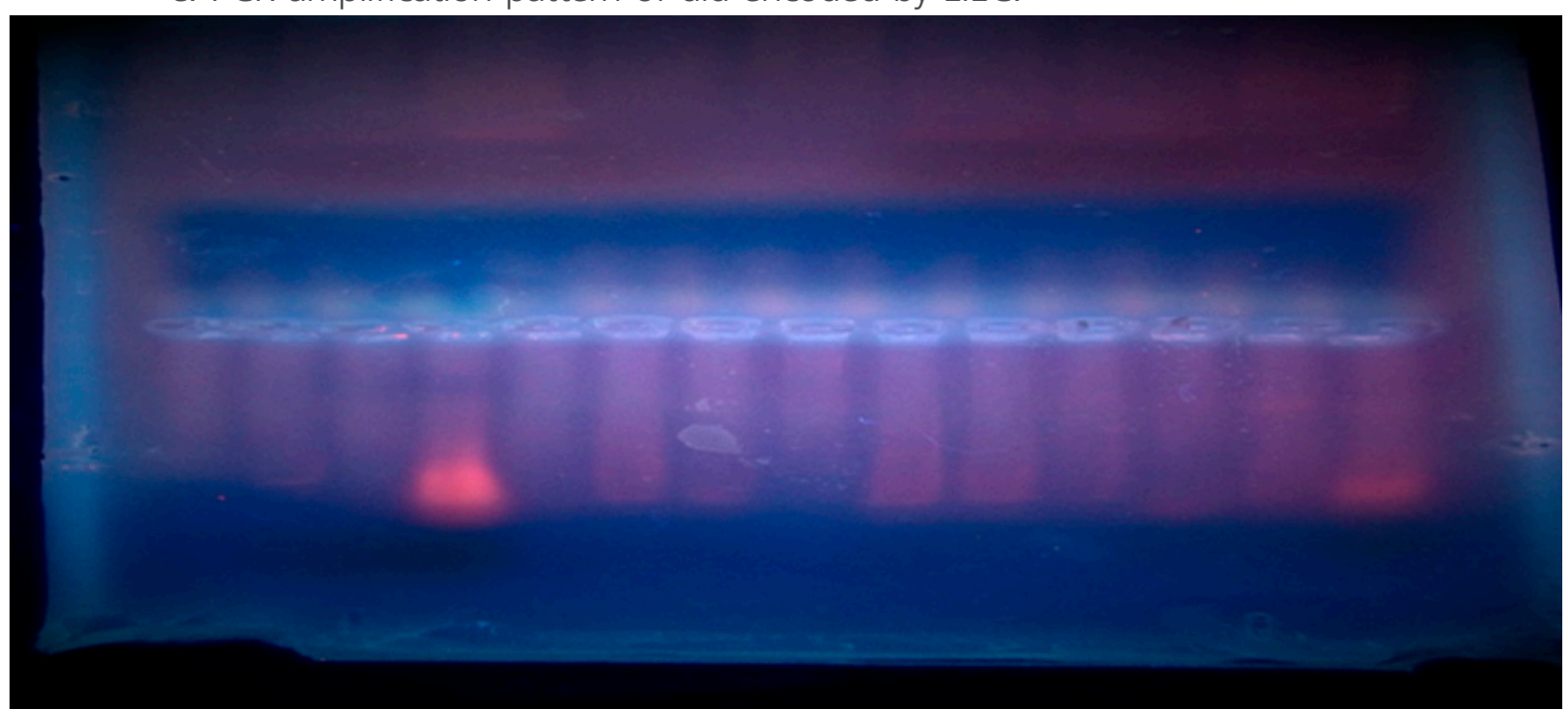




\section{Discussion}

In sub-saharan Africa and most developing and underdeveloped world, diarrhoea- causing- E. coli are a significant cause of morbidity and mortality in young infants. In contrast, adults are usually asymptomatic visible infection in adults is usually self-limiting. However, in the HIVIAIDS patients diarrhoea due to $E$. coli has become a leading cause of morbidity and mortality in adults as well, which is well documented [9]. High levels of HIV IgM in patients with diarrhoea confirm that these patients are in the acute or early stage of HIV infection prior to seroconversion [10]. In this study, these patients were also among those with multiple genes (strains) of $E$. coli. The aetiological fraction of those positive for HIV was more than that of the general population, hence serostatus of the $\mathrm{HIV}^{+}$individuals is likely responsible for diarrhoea in this group of people, and the different $E$. coli virulence genes accounts for this diarrhoea. This result supports the idea that proper management of diarrhoea in the acute phase of HIV infection is necessary, as diarrhoea itself is a serious source of morbidity in those living with HIVIAIDS especially presenting in the early phase of the infection of which this study further confirms an earlier study by Gassama-Sow et al., [2].

There was no significant association between patients' age or sex and $E$. coli strain-specific virulence genes which correlates earlier reports on infants [11]. However, results of a study in Lima, Peru surprisingly deviated from these earlier reports. Medina et al., [12] reported a significant association in both age and sex in E coli carriage when they studied diarrhoea-causing $E$. coli strains in infants. Reports indicate that diarrhoeagenic $E$. coli are moslyt isolated from immunocompromised patients with diarrhoea [13] but strains could vary from regionally; consequently, regional interpretation of results must be taken into account, especially in clinical settings, to enhance proper management of diarrhoea in $\mathrm{HIV}^{+}$ patients. Of patients in Nigeria, this is the first study to genotypically characterize $E$. coli in HIV patients by $E$. coli strain-specific virulent genes. Earlier studies characterized diarhoeagenic E. coli serotypically, and though Nweze [14] identified some of these strains using PCR, the strains were not characterized using the method described here. Okeke et al., [7] used a DNA hybridization technique characterized $E$. coli strains but this does not underscore PCR relative to sensitivity and specificity.

EHEC serotype ECO157:H7 has been detected from various parts of the world from specific outbreaks in the normal population of which infants have been worst hit, including outbreaks reported by Riley et al,. [15] in the United States, by Morgan et al., [16] in Britain, by Effler et al., [17] Swatziland, by Koyange et al., [18] in Democratic Republic of Congo. In Nigeria, a prevalence study of ECO157H7 included report from southwest Nigeria by Ogunsanya et al., [19]; Okeke et al., [7] and; Olorunshola et al., [20].Esumeh et al., [21] also reported a similar high prevalence of ECO157:H7 in Benin City, Nigeria. In this study high prevalence of ECO157:H7 serotype was associated with a high risk population. Although other studies also showed a high prevalence of ECO157:H7, these studies were mainly on infants and not on immunocompromised individuals. We confirm that ECO157:H7 accounted for 81.3\% of diarrhoea cases among $\mathrm{HIV}^{+}$patients even when ECO157:H7 is an emerging EHEC serotype that is not well documented in Nigeria or in other parts of developing world. According to odd- based analysis, ECO157:H7 has the highest ability to diarrhoea among $\mathrm{HIV}^{+}$patients which correspond to a similar result from an earlier report [21]. Hence, isolation of ECO157:H7 depended on the HIV status of the subjects in this study.

EPEC is an important diarrhoeagenic pathogen, which has been recognized as a highly prevalent cause of diarrhoea in Nigeria $[7,14]$. This study also confirmed that EPEC is a major cause diarrhoea since it was detected in $75 \%$ of all the cases. EPEC is an important strain because it is linked to acute 
watery diarrhoea and persistent diarrhoea in infants and in immuno compromised patients, and it leads to high morbidity and mortality rates greater than $50 \%$ in $\mathrm{HIV}^{+}$patients, especially in developing countries [2]. Medina et al., [12] reported that EPEC strains could be a concern for $\mathrm{HIV}^{+}$patients but the study examined only children. Gassama-Sow et al., [2] also showed a high prevalence of EPEC in $\mathrm{HIV}^{+}$ individuals in Senegal which is in agreement with our study and another study in the Netherlands [22].

EHEC which was isolated with high frequency in the HIV cases and in some of the controls was also incriminated in this study as a cause of diarrhoea in $\mathrm{HIV}^{+}$individuals, the odds of causing diarrhoea in the HIV cases was $1.338(\mathrm{Cl}=99 \%)$ though data are scarce with regards of EHEC causing diarrhoea in Nigeria in both adults and infants. Okeke et al., [7] used DNA hybridization and detected EHEC in infants for only a small proportion $(0.5 \%)$ of total positive individuals. The high prevalence in this study may be connected with the fact that the population in this study was immunocompromised and that the PCR method used in this study is more sensitive than the hybridization techniques used by Okeke et al., [7]. The virulence pattern of EHEC has changed with the advent of HIVIAIDS. However, earlier studies by Okeke et al., [7] and Nweze [14] did not distinguish the serotype ECO157:H7 from the EHEC strain.

ETEC, which causes dehydrating diarrhoea because of heat-stable and heat-labile enterotoxins was isolated with low frequency in Nigeria and in $\mathrm{HIV}^{+}$ individuals and was less likely to cause diarrhoea in $\mathrm{HIV}^{+}$individuals ( $\left.\mathrm{Cl}=99 \%\right)$. ETEC has also been isolated with low frequency in infants with diarrhoea in several studies from several geographical locations $[2,7,12,23]$.

Results from this study also incriminated EIEC as a causal strain for diarrhoea in those infected with HIV. Although not much is known about EIEC in Nigeria, deteriorating immune statuses in HIVIAIDS patients have made EIEC an emerging strain, though a study by Gassama-Sow et al., [2] observed that EIEC infection was not dependent on HIV infection according to serostatus, because no asymptomatic carriage was found in their study. They reported that 95 screened $\mathrm{HIV}^{+}$individuals did not present EIEC of the total 182 stool samples. In this study, 30 of the total 833 stool samples yielded EIEC from $\mathrm{Dia}^{+} \mathrm{HIV}^{+}$individuals as compared to 5 from $\mathrm{Dia}^{-}$ $\mathrm{HIV}^{+}$individuals. Coupled with the fact that EIEC is scarcely reported in Nigeria, it is then reasonable to assume that EIEC was a causative agent of diarrhoea in $\mathrm{HIV}^{+}$individuals. Vieira et al., [8] also reported a high prevalence of EIEC in costal Ecuador, though they did not stratify the population. Further, Okeke et al., [7] reported the possibility of EIEC in childhood diarrhoea in Nigeria but very little has been reported about EIEC in Nigeria after 2000. EaggEC and DAEC was not implicated as a probable cause of diarrhoea in this study. Although this strain is also said to be emerging and is not common to Nigeria, more researches should be conducted in the general population.

Multiple infections by different strains did not prove to be a cause of diarrhoea in $\mathrm{HIV}^{+}$individuals or in the general population, as there were too few samples in which multiple strains were detected to determine their collective role in diarrhoea causation. This result supports an earlier report by Gassama-Sow et al., [2] regarding, subjects from Senegal which is also a West African country where geographical data may be similar.

High resistance to tetracycline, cotrimoxazole and ampicillin was observed for EIEC, ECO157:H7, and ETEC strains. This resistance may be due to exposure of the strains to selective pressure since most of these antibiotics are used heavily in the treatment of diarrhoea and are heavily abused.

In conclusion, strains of $E$. coli possess great concern in $\mathrm{HIV}^{+}$especially at the acute phase of HIV infection even before seroconversion and probably through the course of infection. Proper management is highly required in $\mathrm{HIV}^{+}$individuals to redu- 
ce morbidity and mortality. And such management should be geographically considered as different strains may dominate different geographical locations. This will reduce multiple drug resistance currently seen in most strains.

\section{Acknowledgements}

We wish to thank all those involved in the collection of sample in the tertiary health institution. Edittage editing company is highly recognized for a well done job in editing this manuscript. We do not regret patronizing edittage and advised other prospecting authors to look towards edittage.

We however declare no competing interes.

\section{List of abbreviations}

DAEC, diffusely adherent Escherichia coli; Dia`, diarrhoea negative; $\mathrm{Dia}^{+}$, diarrhoea positive; eaeA, attachment and effacing; EaggEC, enteroaggregative E. coli; $\mathrm{EF}$, etiological fraction; $\mathrm{EHEC}$, enterohaemorrhagic E. coli; EIEC, enteroinvasive E. coli; EPEC, enteropathogenic $E$. coli; ETEC, enterotoxigenic $E$. coli; HIV, human immunodeficiency virus; HIV', HIV negative; $\mathrm{HIV}^{+}$, HIV positive; hlyA, haemolysin A; ipa $\mathrm{H}$, invasion plasmid antigen $\mathrm{H}$; OR, odds ratio; slt, shiga-like toxin; stx, shiga toxin

\section{References}

1. Dallabetta GA, Miotti PG. Chronic diarrhoea in AIDs patients in the tropics: a review. Trop Doct. 1992; 22: 3-9.

2. Gassama-Sow A, Sow PS, Guèye M, Guejye-N'diaye A, Perret JL, M'boup S, et al. Characterization of pathogenic Escherichia coli in human immunodeficiency virus-related diarrhoea in Senegal. J Infect Dis. 2004; 189: 75-8.

3. Mathewson JJ, Salameh BM, DuPont HL, Jiang ZD, Nelson AC, Arduino R, et al. HEp-2 cell-adherent Escherichia coli and intestinal secretory immune response to human immunodeficiency virus (HIV) in outpatients with HIV-associated diarrhea. Clin Diagn Lab Immunol. 1998;5: 87-90.

4. Kuhnert P, Boerlin P, Frey J. Target genes for virulence assessment of Escherichia coli isolates from water, food and environment. FEMS Microbiol Rev. 2000; 24: 107-17.

5. Schlager TA, Guerrant RL. Seven possible mechanisms for Escherichia coli diarrhea. Infect Dis Clin North Am. 1988; 2: 60724.

6. Cooper KK, Mandrell RE, Louie JW, Korlach J, Clark TA, Parker CT, et al. Comparative genomics of enterohemorrhagic Escherichia coli 0145: H28 demonstrates a common evolutionary lineage with Escherichia coli O157: H7. BMC Genomics. 2014;15: 17 Available from: http://www.biomedcentral.com/14712164/15/17

7.Okeke IN, Lamikanra A, Steinrück H, Kaper JB. Characterization of Escherichia coli strains from cases of childhood diarrhea in provisional southwestern Nigeria. J Clin Microbiol. 2000; 38: 7-12.

8. Vieira N, Bates SJ, Solberg OD, Ponce K, Howsmon R, Cevallos $W$, et al. High prevalence of enteroinvasive Escherichia coli isolated in a remote region of northern coastal Ecuador. Am J Trop Med Hyg. 2007; 76: 528-33.

9. Mossoro C, Glaziou P, Yassibanda S, Lan NT, Bekondi C, Minssart $P$, et al. Chronic diarrhea, hemorrhagic colitis, and hemolytic uremic syndrome associated with HEp-2 adherent Escherichia coli in adults infected with human immune deficiency virus in Bangui, Central African Republic. J Clin Microbiol. 2002; 40: 3086-8.

10. Cohen MS, Gay CL, Busch MP, Hecht FM. The detection of acute HIV infection. J Infect Dis. 2010;202 Suppl 2: S270-7.

11. Ochoa TJ, Ecker L, Barletta F, Mispireta ML, Gil Al, Contreras C, et al. Age-related susceptibility to infection with diarrheagenic Escherichia coli among infants from Periurban areas in Lima Peru. Clin Infect Dis. 2009; 49: 1694-702.

12. Medina et al. 2010.

13. Cohen MB, Nataro JP, Bernstein DI, Hawkins J, Roberts N, Staat MA. Prevalence of diarrheagenic Escherichia coli in acute childhood enteritis: a prospective controlled study. J Pediatr. 2005; 146: 54-61. 
14. Nweze El. Aetiology of diarrhoea and virulence properties of diarrhoeagenic Escherichia coli among patients and healthy subjects in southeast Nigeria. J Health Popul Nutr. 2010; 28: 245-52.

15. Riley LW, Remis RS, Helgerson SD, McGee HB, Wells JG, Davis BR, Herbert RJ, Olcott ES, Johnson LM, Hargrett NT, Blake PA, Cohem ML. Hemorrhagic colitis associated with a rare Escherichia coli serotype. N. Eng. Med.1983; 308 (12); 681-5.

16. Morgan GN, Newman C, Palmer SR, Allen JB, Shepard W, Rampling AM, Warren RE, Gross RJ, Scotland SM, Smith HR. Epidemiol. Infect. 1988; 101: 83-91.

17. Effler EM, Isaacson $L$, Arten $R$, Heenan $P$, Canter $P$, Barret $T$, Griffin PM. Emerging Infect. Dis. 2001; 7: 812-819.

18. Koyange L, Olivier G, Muyembe JJ, Kebeba B, Gonaliz M, Germani Y Enterohemorrhagic Escherichia coli O157, Kinshasa et al. 2001.

19. Ogunsanya TI, Rotimi VO, Adenuga A. A study of the aetiological agents of childhood diarrhoea in Lagos, Nigeria. J Med Microbiol. 1994; 40: 10-4.

20. Olorunshola ID, Smith SI, Coker AO. Prevalence of EHEC 0157: $\mathrm{H} 7$ in patients with diarrhoea in Lagos, Nigeria. APMIS. 2000; 108: $761-3$.

21. Esumeh FI, Isibor JO, Egbagbe IDS. Screening for Escherichia coli 0157: H7 in diarrhearic patients in Benin City, Nigeria. J Microbiol. Biotech. Res. 2011; 1: (4), 1-4.

22. Schultsz C, Snijders F, Dankert J. No evidence for a role of enteroadherent Escherichia coli in diarrhea in human immunodeficiency virus-infected patients. J Infect Dis. 1996; 174: 246.

23. Nguyen TV, Le Van P, Le Huy C, Gia KN, Weintraub A. Detection and characterization of Diarrheagenic Escherichia coli from young children in Hanoi, Vietnam. J Clin Microbiol. 2005; 43: 755-60.

\section{Comment on this article:}
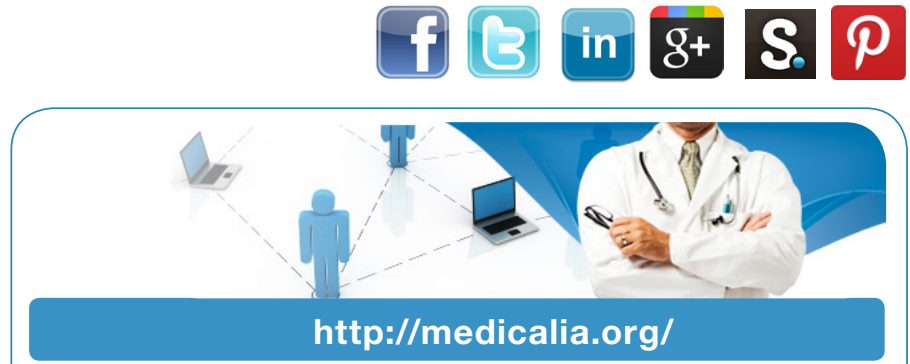

Where Doctors exchange clinical experiences, review their cases and share clinical knowledge. You can also access lots of medical publications for free. Join Now!

\section{Publish with iMedPub}

http://www.imed.pub

International Archives of Medicine is an open access journal publishing articles encompassing all aspects of medical science and clinical practice. IAM is considered a megajournal with independent sections on all areas of medicine. IAM is a really international journal with authors and board members from all around the world. The journal is widely indexed and classified Q1 in category Medicine. 